\title{
Evaluation of the hepatoprotective effect of methanolic extract of Caulerpa lentillifera against acetaminophen-induced liver toxicity in juvenile zebrafish (Danio rerio)
}

\author{
Kimberly D. Codorniz, Rose Emielle M. Marquina, Alexandra Dominique G. Nolasco, \\ Paula Denise D. Palencia, Sigfredo B. Mata, $\mathrm{RPh}^{*}$ \\ College of Pharmacy, De La Salle Medical and Health Sciences Institute, City of Dasmariñas, 4114 \\ Cavite, Philippines \\ *Corresponding author: sbmata@dlshsi.edu.ph
}

\begin{abstract}
Background: Liver injury is a common reason for drugs to be withdrawn from the market. Treatment options for common liver disease are limited, and therapy with modern medicines may lack effectiveness. Caulerpa lentillifera may have strong antioxidant systems that protect the plant from oxidative damage caused by the environment.

Objectives: The main objective of this study was to evaluate the hepatoprotective effect of the methanolic extract of $C$. lentillifera against acetaminophen-induced liver toxicity in juvenile zebrafish (Danio rerio).

Methods: Juvenile zebrafish (aged 1-3 months) were exposed to $10 \mu \mathrm{M}$ and $25 \mu \mathrm{M}$ acetaminophen ( $N$ acetyl-p-aminophenol; APAP) to induce liver damage. C. lentillifera methanolic extracts $(10 \mu \mathrm{g} / \mathrm{L}, 20$ $\mu \mathrm{g} / \mathrm{L}$ and $30 \mu \mathrm{g} / \mathrm{L}$ ), were concomitantly added to individual tanks containing $10 \mu \mathrm{M}$ or $25 \mu \mathrm{M} \mathrm{APAP}$. The positive control group was treated with $N$-acetylcysteine/NAC $(10 \mu \mathrm{M})$ and silymarin $(10 \mu \mathrm{g} / \mathrm{L}, 20$ $\mu \mathrm{g} / \mathrm{L}$ and $30 \mu \mathrm{g} / \mathrm{L}$ ). Hematoxylin and Eosin (H\&E) staining revealed the extent of liver injury through the presence of hepatic necrosis, vacuolization, leukocyte infiltration, and ballooning. The antioxidant mechanism of hepatoprotective activity was assessed by a DPPH free radical scavenging assay.

Results: $C$. lentillifera extracts reduced the mortality of juvenile zebrafish when simultaneously exposed to $10 \mu \mathrm{M}$ and $25 \mu \mathrm{M}$ APAP. Upon histopathological examination of the liver tissue of juvenile zebrafish, the group treated with the $10 \mu \mathrm{M}$ APAP together with the highest concentration $(30 \mu \mathrm{g} / \mathrm{L})$ of C. lentillifera extract showed minimal liver injury compared to the groups exposed to $25 \mu \mathrm{M}$ APAP. However, the DPPH free radical scavenging assay performed using $24-36 \mathrm{mg} / \mathrm{mL}$ C. lentillifera extracts showed a minimal effect on the free radical scavenging activity.

Conclusion: The histopathological analysis of the liver showed that C. lentillifera extract prevented the progression of liver damage caused by APAP. The results of DPPH free radical scavenging assay indicated that the hepatoprotective activity of $C$. lentillifera extract might have other antioxidant mechanisms aside from free radical scavenging. In order to effectively assess the improvement in the survival rate of juvenile zebrafish, longer exposure in the treatments is recommended.
\end{abstract}

Keywords: $C$. lentillifera; juvenile zebrafish; hepatoprotective; drug-induced liver injury (DILI)

\section{Introduction}

Investigatory drugs are usually withdrawn in drug development and preclinical studies as well as after drug approval and marketing because of their ability to induce hepatotoxicity. Druginduced liver injury results when the liver is unable to detoxify free radicals, such as reactive oxygen species (ROS), or other toxic metabolites from drug substances. This type of liver injury is a growing medical, scientific, and public health problem (Suk \& Kim, 2012). Treatment choices for common liver injury are limited, and therapy with modern medicines may lack effectiveness. $N$ - 
acetylcysteine (NAC) is widely accepted in the prevention of hepatic injury due to acetaminophen overdose (Heard, 2008). A known hepatoprotective compound, silymarin from Silybum marianum, has an ability to inhibit the free radicals that are produced from the metabolism of toxic drug substances, including acetaminophen (Vargas-Mendoza et al., 2014).

Currently, there is a growing interest in the study of the antioxidant properties of marine species, such as algae, because of their inherent capability to withstand oxidative damage in the aquatic environment. Caulerpa lentillifera, known locally as latô, is commonly eaten as salad in the Philippines, and may have strong antioxidant systems that protect it from oxidative damage. Phenolic antioxidants found in C. lentillifera may become a possible agent used for the prevention of hepatotoxicity (Nguyen et al., 2011). Rodents are traditionally used in toxicological studies of the liver, but recently, small fish such as zebrafish (Danio rerio) have been used as an animal model as they present advantages, such as short generation time, high fertility, and low operational cost in terms of housing space and daily maintenance. In many liver toxicological studies, zebrafish larvae are utilized because they are optically clear and their internal organs can be directly observed without the need for dissection. Thus, real-time, simultaneous monitoring of livers in zebrafish larvae is easily achieved. Zebrafish therefore become an increasingly more valuable animal model than rodents in certain vertebrate toxicological studies (Asaoka et al., 2013). The main objective of this study was to determine the effect of $C$. lentillifera methanolic extract in reducing acetaminophen-induced liver toxicity in juvenile zebrafish (Danio rerio).

\section{Methods}

\subsection{Collection and preparation of C. lentillifera extract}

All seaweed specimens were collected from Barangay Talaba I in the City of Bacoor, Province of Cavite during the month of October 2018. They were immediately washed with tap water, dried, placed in wide-mouthed plastic containers covered with ice, and transported. A sample was authenticated at the Bureau of Fisheries and Aquatic Resources (BFAR) in Diliman, Quezon City. Each C. lentillifera specimen was washed in situ with distilled water, lyophilized at $70^{\circ} \mathrm{C}$ for 7 days, and pulverized using a household blender. Methanolic extract was then prepared by maceration of the lyophilized and pulverized seaweed at $50^{\circ} \mathrm{C}$ with sonication for 1 hour. This was then subjected to rotary evaporation to remove the solvent methanol at $40^{\circ} \mathrm{C}$ and $70 \mathrm{rpm}$. The extract was dissolved in appropriate solvents for the bioassay and DPPH antioxidant assay. 


\subsection{Collection, acclimatization, and treatment of zebrafish}

A total of 720 juvenile zebrafish (1 to 3 months old) was used in the study. Standard housing and treatment protocols were followed. The zebrafish were maintained in aerated water in the laboratory at $28 \pm 2^{\circ} \mathrm{C}$ in a $14 \mathrm{hr} / 10 \mathrm{hr}$ light/dark cycle photoperiod and fed twice a day with fish food (sinking pellets) for 2 weeks. All zebrafish used in this study were healthy and free of any signs of disease.

After the acclimatization period, fish were randomly assigned into 24 experimental tanks, with a density of 10 zebrafish per $2 \mathrm{~L}$. All treatments were done in triplicate and conducted for a total of 72 hours with twice daily feeding and regular fish tank maintenance. Stock solutions of treatments (APAP, NAC, silymarin, and $C$. lentillifera) were directly added into the fish tank water to make specified concentrations. In order to induce liver damage, the zebrafish were exposed to 10 $\mu \mathrm{M}$ and $25 \mu \mathrm{M}$ APAP. C. lentillifera methanolic extracts $(10 \mu \mathrm{g} / \mathrm{L}, 20 \mu \mathrm{g} / \mathrm{L}$ and $30 \mu \mathrm{g} / \mathrm{L})$, were concomitantly added to individual tanks containing $10 \mu \mathrm{M}$ or $25 \mu \mathrm{M}$ APAP. Similar experiments were conducted for NAC $(10 \mu \mathrm{M})$ and silymarin $(10 \mu \mathrm{g} / \mathrm{L}, 20 \mu \mathrm{g} / \mathrm{L}$ and $30 \mu \mathrm{g} / \mathrm{L})$ replacing $C$. lentillifera extracts. The groups were observed every 12 and 24 hrs for fish movement and mortality for 3 days. Live zebrafish were sacrificed through hypothermic shock in ice water for the histological examination.

\subsection{Histological analysis}

Whole body histological sections (7- $\mu$ m sections) showing the liver were taken from the tail region behind the anus as prescribed by a histopathologist and using a standard protocol. Briefly, the fish was stored in Dietrich's fixative (28.5\% ethanol, $1 \%$ formalin, $0.2 \%$ acetic acid) at a room temperature for several days and processed by a tissue processor (containing 70\%, 80\%, and 95\% ethanol gradient) for dehydration. Ethanol was removed by immersing the cassettes in 100\% xylene for $1 \mathrm{hr}$. The tissue was embedded in paraffin wax for $2 \mathrm{hrs}$ at $56^{\circ} \mathrm{C}$ and allowed to solidify. Sectioning was performed using Leica microtome. Tissue sections were stained using the hematoxylin and eosin (H \& E) staining method by Ellis and Yin (2017).

\subsection{DPPH free radical scavenging assay}

The free radical scavenging activity of the $C$. lentillifera extracts were analyzed according to the method described by Müller et al. (2011) with the modifications from Osuna-Ruiz et al. (2016). DPPH free radical scavenging assay was also conducted to determine if the extract has the ability to scavenge free radicals as a hepatoprotective mechanism. C. lentillifera extracts $(24 \mathrm{mg} / \mathrm{mL}, 27$ $\mathrm{mg} / \mathrm{mL}, 30 \mathrm{mg} / \mathrm{mL}, 33 \mathrm{mg} / \mathrm{mL}$ or $36 \mathrm{mg} / \mathrm{mL}$ ) and L-ascorbic acid as the standard were separately incubated with $0.1 \mathrm{mM}$ DPPH (2,2-diphenyl-1-picrylhydrazyl radical) in 1:1 hexane:methanol for 30 
min in the dark and at a room temperature. The absorbance of the mixtures was determined at 540 $\mathrm{nm}$ using a UV/Vis spectrophotometer (Hitachi U-2910). When DPPH free radical scavengers reacted with the purple-colored DPPH, it was converted into its reduced form, which was yellow in color. This resulted in a decrease in absorbance at $540 \mathrm{~nm}$. The percentage inhibition was determined using the formula:

$$
\% \text { Inhibition }=\frac{A_{\text {negative control }}-\left(A_{\text {sample }}-A_{\text {blank }}\right)}{A_{\text {negative control }}} \times 100 \%
$$

where:

$A_{\text {negative control }}=$ mean absorbance of DPPH solution in methanol

Asample $\quad=$ mean absorbance of DPPH solution with $C$. lentillifera extract (or standard, L-ascorbic acid solution)

Ablank $\quad=$ mean absorbance of $C$. lentillifera extract (or L-ascorbic acid solution)

\section{Results and discussion}

The number of deaths in the APAP-treated control group doubled with the increase in the concentrations of APAP from $10 \mu \mathrm{M}$ to $25 \mu \mathrm{M}$. When zebrafish were exposed to the negative control (the solvent used in preparing treatments), NAC, silymarin, or C. lentillifera extract, no zebrafish deaths were observed at the end of 72 hours. This means that exposure to the treatment groups alone and not in combination with APAP did not adversely affect the survival rate of the zebrafish. Similar to NAC and silymarin, which are known as hepatoprotective agents, $C$. lentillifera extracts reduced the mortality of juvenile zebrafish when simultaneously exposed to $10 \mu \mathrm{M}$ and $25 \mu \mathrm{M}$ APAP.

The histological characteristics of the zebrafish livers were assessed using H \& E staining. Liver injury was indicated when hepatic necrosis, leukocyte infiltration and hepatocyte swelling were observed in the fish sections. The latter was seen as sinusoid compression due to swollen hepatocytes (Ellis \& Yin, 2017). APAP treatment showed these signs of liver injury (Figure 1). All of the observed effects of acetaminophen in zebrafish hepatocytes were consistent with previously observed effects in human liver cells. APAP-induced liver injury is known to activate neutrophils, leading to neutrophil accumulation in the hepatic vasculature. Following APAP administration, a significant number of neutrophils are recruited into the liver resulting in subsequent development of hepatocellular injury between 4 and $24 \mathrm{hrs}$ after drug treatment (Xu, et al., 2014).

To ascertain that NAC, silymarin, and C. lentillifera extract did not adversely affect the zebrafish liver when given in the absence of liver damaging APAP, controls were set up. Zebrafish groups treated with $10 \mu \mathrm{M} \mathrm{NAC}, 10$ and $20 \mu \mathrm{g} / \mathrm{L}$ silymarin, and 10-30 $\mu \mathrm{g} / \mathrm{L}$ C. lentillifera did not show any remarkable hepatocyte changes compared with the negative control containing only $0.1 \%$ by volume DMSO, the solvent used in preparing these solutions (Figure 2). 


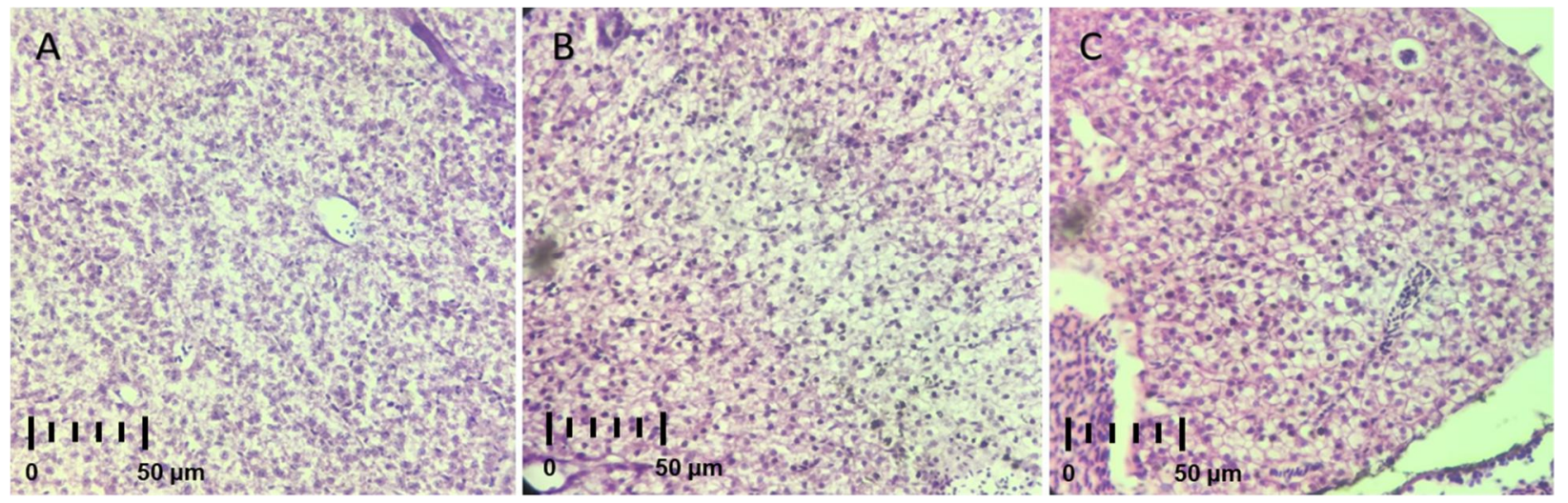

Figure 1. Exposure to APAP causing hepatic damage (400x magnification). Hepatic tissue of zebrafish from the negative control group (A), after exposure to $10 \mu \mathrm{M}$ APAP (B), and after exposure to $25 \mu \mathrm{M}$ APAP (C)
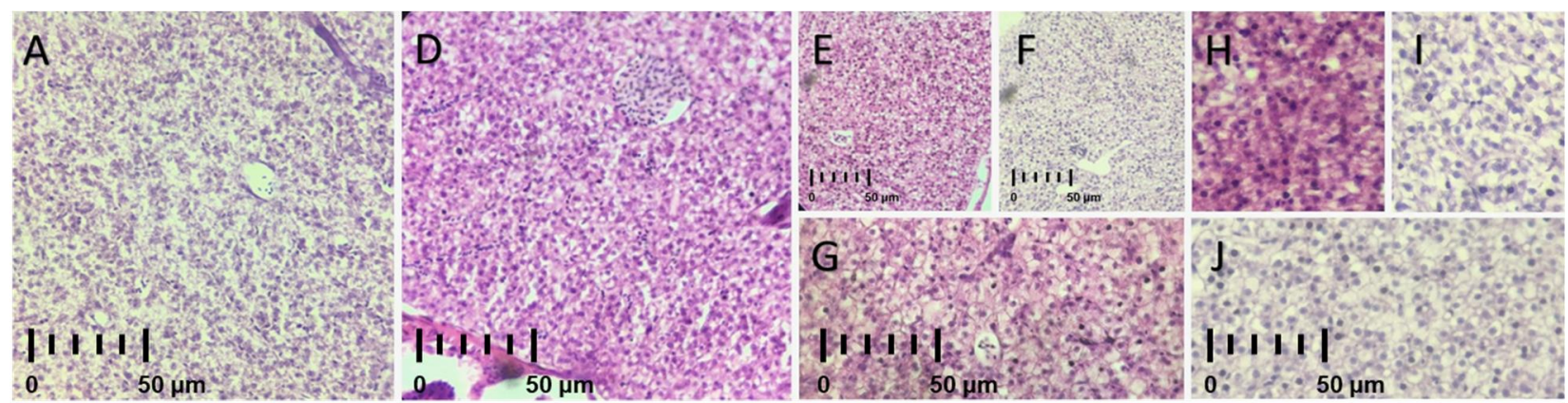

Figure 2. Treatment insignificantly affecting hepatic cells without exposure to APAP (400x magnification). Negative control (A), $10 \mu \mathrm{M}$ NAC (D), $10 \mu \mathrm{g} / \mathrm{L}$ silymarin (E), $20 \mu \mathrm{g} / \mathrm{L}$ silymarin (F), $30 \mu \mathrm{g} / \mathrm{L}$ silymarin (G), 10 $\mu \mathrm{g} / \mathrm{L}$ C. lentillifera extract (H), $20 \mu \mathrm{g} / \mathrm{L}$ C. lentillifera extract (I), and $30 \mu \mathrm{g} / \mathrm{L}$ C. lentillifera extract (J)

The liver histopathological features of juvenile zebrafish exposed to $10 \mu \mathrm{M}$ APAP and concurrently treated with NAC $(10 \mu \mathrm{M})$, silymarin $(10-30 \mu \mathrm{g} / \mathrm{L})$ or C. lentillifera extract (10-30 $\mu \mathrm{g} / \mathrm{L})$ showed a decrease in hepatic necrosis, leukocyte infiltration, hepatocyte vacuolization, and hepatocyte swelling in varying degrees consistent with their concentrations (Figure 3). However, hepatic tissues of zebrafish exposed to a higher concentration of APAP (25 $\mu \mathrm{M})$ showed minimal changes on the hepatic cellular structures in the presence of the given treatments (NAC, silymarin, and $C$. lentillifera extract). These indicate that hepatic damage from exposure of zebrafish to $25 \mu \mathrm{M}$ of APAP is irreversible with any of the known hepatoprotective agents (NAC and silymarin) and the investigational extract, $C$. lentillifera.

Treatment of zebrafish exposed to $10 \mu \mathrm{M}$ APAP with $30 \mu \mathrm{g} / \mathrm{L} C$. lentillifera extract showed no hepatic necrosis but minimal leukocyte infiltration and vacuolization. These were similar to those observed in $30 \mu \mathrm{g} / \mathrm{L}$ silymarin, possibly indicating that these plant extracts might share a similar hepatoprotective mechanism. The hepatoprotective properties of NAC and silymarin are well 
established and appear to be partly related to their antioxidant activities. NAC is thought to reverse APAP-induced hepatotoxicity by replenishing glutathione, reducing the hepatotoxic metabolite of APAP, $N$-acetyl- $p$-benzoquinone imine (NAPQI), and effecting nonspecific hepatoprotective actions related to its antioxidant properties (Tardiolo, 2018). Silymarin extract contains a mixture of isomeric flavonolignans. Due to their phenolic structures, silymarin flavonoids have been reported to have antioxidant properties, which can control or inhibit free radicals produced by the hepatic metabolism of toxic substances such as APAP. In addition, the hepatoprotective activity of silymarin is shown to be caused by the maintenance of hepatocyte membrane integrity, affecting intracellular glutathione inhibition of leukotrienes and cyclooxygenase (Vargas-Mendoza, 2014). Flavonoids, which are previously reported to be present in $C$. lentillifera, may also be responsible for the observed hepatoprotective property of $C$. lentillifera (Nguyen, et al., 2011).

To determine if the hepatoprotective property of $C$. lentillifera was mediated by a free radical scavenging mechanism, the DPPH assay was performed. However, the DPPH free radical scavenging assay performed using $24-36 \mathrm{mg} / \mathrm{mL}$ C. lentillifera extracts showed a minimal effect on the free radical scavenging activity (Table 1). This was found to be consistent with a previous study by Nguyen, et al. (2011), indicating that the hepatoprotective activity of $C$. lentillifera extract might have other antioxidant mechanisms aside from free radical scavenging.

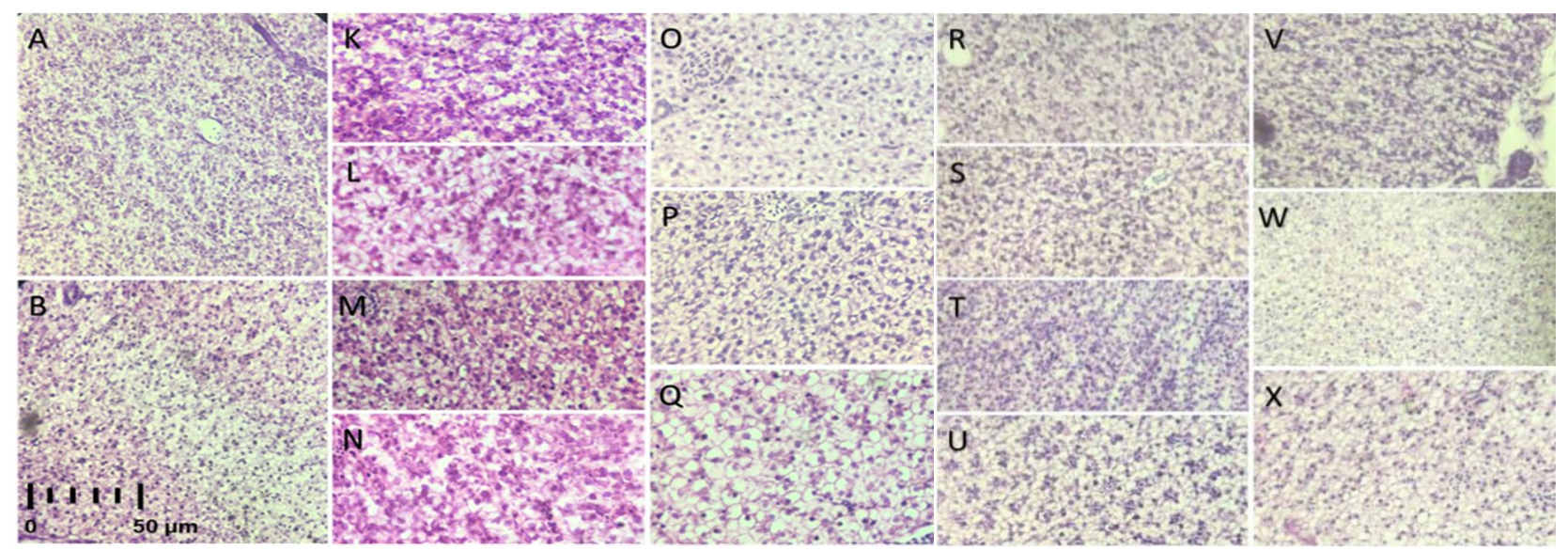

Figure 3. C. lentillifera reducing hepatic tissue injury after exposure of zebrafish to $10 \mu \mathrm{M} A P A P(K-Q)$ and 25 $\mu \mathrm{M}$ APAP (R-X) (400x magnification). Negative control (A), $10 \mu \mathrm{M}$ APAP (B), with $10 \mu \mathrm{M} N$-acetylcysteine (K), with $10 \mu \mathrm{g} / \mathrm{L}$ silymarin (L), with $20 \mu \mathrm{g} / \mathrm{L}$ silymarin (M), with $30 \mu \mathrm{g} / \mathrm{L}$ silymarin (N), with $10 \mu \mathrm{g} / \mathrm{L} C$. lentillifera extract (O), with $20 \mu \mathrm{g} / \mathrm{L}$ C. lentillifera extract (P), with $30 \mu \mathrm{g} / \mathrm{L}$ C. lentillifera extract (Q), with 10 $\mu \mathrm{M} N$-acetylcysteine (R), with $10 \mu \mathrm{g} / \mathrm{L}$ silymarin (S), with $20 \mu \mathrm{g} / \mathrm{L}$ silymarin (T), with $30 \mu \mathrm{g} / \mathrm{L}$ silymarin (U), with $10 \mu \mathrm{g} / \mathrm{L}$ C. lentillifera extract (V), with $20 \mu \mathrm{g} / \mathrm{L}$ C. lentillifera extract (W), with $30 \mu \mathrm{g} / \mathrm{L}$ C. lentillifera extract $(\mathrm{X})$ 
Table 1. Percentage Inhibition of Free Radical Activity Using DPPH Assay

\begin{tabular}{|c|c|c|}
\hline \multirow{2}{*}{$\begin{array}{c}\text { Concentration } \\
(\mathbf{m g} / \mathbf{m L})\end{array}$} & \multicolumn{2}{|c|}{ Percentage Inhibition } \\
\cline { 2 - 3 } & L-Ascorbic Acid Standard & C. lentillifera Extract \\
\hline 24.0 & 96.1 & 29.7 \\
\hline 27.0 & 95.9 & 17.1 \\
\hline 30.0 & 97.5 & 20.4 \\
\hline 33.0 & 97.5 & 5.6 \\
\hline 36.0 & 97.3 & 43.2 \\
\hline
\end{tabular}

\section{Conclusion}

After 72 hours of exposure to $10 \mu \mathrm{M}$ and $25 \mu \mathrm{M}$ APAP, zebrafish showed an increased mortality rate with increasing APAP concentrations. Concurrent treatment with NAC, silymarin, and C. lentillifera extract for 72 hours resulted in zero deaths. C. lentillifera might have a potent hepatoprotective property similar to known hepatoprotective agents, NAC and silymarin. The histopathological analysis of the hepatic tissues showed that $C$. lentillifera extracts (at 10-30 $\mu \mathrm{g} / \mathrm{L}$ ) prevented the progression of hepatic damage caused by $10 \mu \mathrm{M}$ APAP. The results of DPPH free radical scavenging assay indicated that the hepatoprotective activity of $C$. lentillifera extract might have other antioxidant mechanisms aside from free radical scavenging. In addition, the concentration of the extract might be insufficient to show its antioxidant activity.

In order to effectively assess the improvement in the survival rate of juvenile zebrafish, longer exposure in the treatments is recommended. Additional antioxidant assays may be performed on the methanolic extract of $C$. lentillifera to determine its mechanism of hepatoprotective activity.

\section{Acknowledgment}

We would like to thank the faculty and staff of the De La Salle Medical and Health Sciences Institute College of Pharmacy and College of Medical Laboratory Science for the technical support in completing this research. We would also like to express our gratitude to the organizers of the $5^{\text {th }}$ Asian Young Pharmacists Group (AYPG) Leadership Summit and the Indonesian Young Pharmacists Group for accepting this research paper for oral presentation in the summit.

\section{References}

Asaoka, Y., Terai, S., Sakaida, I., \& Nishina, H. (2013). The expanding role of fish models in understanding non-alcoholic fatty liver disease. Dis. Model Mech., 6(4), 905-914.

Ellis, J. L., \& Yin, C. (2017). Histological Analyses of Acute Alcoholic Liver Injury in juvenile zebrafish. J. Vis. Exp. (JoVE), 123, 55630.

Heard, K.J. (2008), Acetylcysteine for Acetaminophen Poisoning. N. Engl. J. Med., 359(3), 285-292. 
Müller, L., Frohlich, K., \& Bohm, V. (2011). Comparative antioxidant activities of carotenoids measured by ferric reducing antioxidant power (FRAP), ABTS bleaching assay ( $\alpha$ TEAC), DPPH assay and peroxyl radical scavenging assay. Food Chem., 123, 315-324.

Nguyen, V.T., Ueng, J.P. \& Tsai, G.J. (2011). Proximate Composition, Total Phenolic Content, and Antioxidant Activity of Seagrape (Caulerpa lentillifera). J. Food Sci., 76(7), C950-C958.

Osuna-Ruiz, I., López-Saiz, C.M., Buros-Hernánddez, A., Velázquez, C., Nieves-Soto, M., \& Hurtado-Oliva, M.A. (2016). Antioxidant, antimutagenic and antiproliferative activities in selected seaweed species from Sinaloa, Mexico. Pharm. Biol., 54(10), 2196-210.

Suk, K. T., \& Kim, D. J. (2012). Drug-induced liver injury: present and future. Clin. Mol. Hepatol., 18(3), 249-257.

Tardiolo, G., Bramanti, P., \& Mazzon, E. (2018). Overview on the Effects of $N$-Acetylcysteine in Neurodegenerative Diseases. Molecules, 23(12), 3305.

Vargas-Mendoza, N., Madrigal-Santillán, E., Morales-González, Á., Esquivel-Soto, J., Esquivel-Chirino, C., García-Luna y González-Rubio, M., Gayosso-de-Lucio, J.A., \& Morales-González, J.A. (2014) Hepatoprotective effect of silymarin. World J. Hepatol., 6(3), 144-149.

Xu, R., Huang, H., Zhang, Z., \& Wang, F. S. (2014). The role of neutrophils in the development of liver diseases. Cell. Mol. Immunol., 11(3), 224-231. 